\title{
Normal 24-hour Ambulatory Esophageal pH Values in Koreans
}

\author{
Won Moon*, Moo In Park*, Gyung Mi Kim*, Kyu Jong Kim*, Seun Ja Park*, Hyo Sung Mun ${ }^{\dagger}$, \\ and Kang Dae Lee ${ }^{\ddagger}$ \\ Departments of *Internal Medicine, ${ }^{\dagger}$ Otorhinolaryngology and ${ }^{\dagger}$ Head and Neck Surgery, Kosin University College of Medicine, Busan, Korea
}

Background/Aims: Twenty-four-hour ambulatory esophageal $\mathrm{pH}$ monitoring is considered the gold standard for diagnosing gastroesophageal reflux disease. The aim of this study was to quantify normal distal esophageal acid parameters in healthy Koreans. Methods: Thirty healthy adults who were not on medication and were free from gastrointestinal symptoms were analyzed. Ambulatory esophageal acid $(\mathrm{pH}<4)$ exposure parameters were recorded at $5 \mathrm{~cm}$ above the lower esophageal sphincter. Results: The 95th percentiles for reflux parameters assessed in the distal esophagus were as follows: percentage of total time with $\mathrm{pH}<4,5.10 \%$; percentage of upright time with $\mathrm{pH}<4,7.88 \%$; percentage of supine time with $\mathrm{pH}<4,4.00 \%$; number of reflux episodes, 62.7; number of reflux episodes with $\mathrm{pH}<4$ for $>5$ minutes, 5.3; and the longest single acid-exposure episode, 21.3 minutes. Conclusions: Physiological gastroesophageal reflux occurs frequently in healthy Koreans. These data provide a reference range that could be utilized in studies involving Korean subjects. (Gut and Liver 2008;2:8-13)

Key Words: Esophageal pH monitoring; Gastroesophageal reflux; Reference values; Esophageal sphincter

\section{INTRODUCTION}

Ambulatory esophageal $\mathrm{pH}$ recording, using a catheter with built-in $\mathrm{pH}$ electrode connected to a digitized solid-state recorder, is a commonly employed test. It provides quantitative data on both esophageal acid exposure as well as the temporal correlation between symptoms and actual reflux events. Since reflux is a physiological event even in normal subjects, delineation between physiological and pathological reflux is often difficult. ${ }^{1}$ Good temporal correlation between a well-defined pathological event such as chest pain, and a decrease in $\mathrm{pH}$ shown on the recording provides evidence of pathogenicity. ${ }^{2,3}$ However, in the absence of symptomatic correlation, esophageal acid exposure may be the only quantifiable parameter to determine abnormality. Johnson and Demeester ${ }^{4}$ have derived a composite score for esophageal acid exposure based on six variables: (1) percent total time $\mathrm{pH}$ $<4$; (2) percent upright time $\mathrm{pH}<4$; (3) percent recumbent time $\mathrm{pH}<4$; (4) number of reflux episodes; (5) number of reflux episodes with $\mathrm{pH}<4$ for more than 5 minutes; and (6) the longest single acid exposure episode. Richter et al. ${ }^{5}$ defined a similar set of normal values in another population studied. It is possible that population differences in gastroesophageal reflux may exist and it is important that standard reference ranges are established for different populations. There is rare previously published study on normal reflux parameters in Korean. This study aims to establish normal values for gastroesophageal acid exposure in healthy Korean residents.

\section{MATERIALS AND METHODS}

\section{Patients}

The study design was approved by the research and ethics committee of the Faculty of Medicine, Kosin University Gospel Hospital, Busan, Korea. Healthy subjects were recruited by advertisement. Each volunteer was carefully interviewed and underwent physical examination to exclude systemic disorders affecting esophageal mo-

Correspondence to: Moo In Park

Division of Gastroenterology, Department of Internal Medicine, Kosin University Gospel Hospital, 34, Amnam-dong, Seo-gu, Busan 602-702, Korea

Tel: +82-51-990-6719, Fax: +82-51-990-5055, E-mail: mipark@ns.kosinmed.or.kr

Received on June 11, 2007. Accepted on March 3, 2008. 
tility and reflux. The inclusion criteria of volunteers were 20-65 years old, healthy men and women free from upper gastrointestinal and airway complaints as 0 point of total score of reflux symptom index, significant sign of laryngeal disease on laryngoscopic examination as $<8$ points of reflux finding score, and esophageal and gastric organic disease including asymptomatic esophagitis, hiatal hernia, gastric ulcer, and duodenal ulcer on upper endoscopic examination. ${ }^{6,7}$ The exclusion criteria were persons on regular medication affecting esophageal motility or gastric acidity or occasional intake within 1 week of the study, smoker, medical student and hospital employee.

\section{Procedure}

The ambulatory esophageal $\mathrm{pH}$ studies were completed as an outpatient procedure. Patients arrived at the motility laboratory, Kosin University Gospel Hospital after an overnight fast. All participants underwent an esophageal manometry before the ambulatory esophageal $\mathrm{pH}$ studies. Manometry was carried out with a multilumen catheter assembly with side holes connected to transducers placed at the esophageal level of the subject in supine position. The catheter was introduced via the nose. Each channel was perfused with $0.5 \mathrm{ml}$ of water per minute via a low-compliance capillary system (Arndorfer Inc.). All pressure recordings were traced on line on a computerized system (Synectics Polygraph, Stockholm, Sweden). After calibration of the measuring device, the pressure characteristics of the gastro-esophageal junction were measured with a station pull-through technique. The probe, which had three side holes circumferentially positioned 120 apart, was stepwise withdrawn, $0.5 \mathrm{~cm}$ at a time, and kept at each level for at least $30 \mathrm{sec}$ or until the recording became stable. The high-pressure zone was defined as the mean of the highest pressure plateaus recorded by each of the three ports minus the mean pressure in the gastric fundus, both measured at the end of expiration. The location of the upper esophageal sphincter was determined with a stepwise withdrawal through the high-pressure zone. In the esophageal body pressure registrations were performed with a multi-lumen catheter with six channels situated $5 \mathrm{~cm}$ apart. The catheter was placed with four channels distributed within the length of the esophageal body. Ten wet swallows of $5 \mathrm{ml}$ water at room temperature and three dry swallows were performed with at least 15 -sec intervals. The mean contraction amplitude was calculated for the 10 wet swallows as the peak pressure in relation to the end-expiratory intraluminal pressure of the esophageal body. The frequency of simultaneous contractions, failed primary peristalsis, nonpropulsive contractions, and interrupted contractions was also registered, as was the proportion of effective and non-effective contractions.

One channel glass $\mathrm{pH}$ probe with internal references (Jubileum single use glass $\mathrm{pH}$ catheter, Microbioprobe and telemedicine s.r.l, Venezia, Italy) were used. Before and after each study, the $\mathrm{pH}$ electrodes were calibrated using buffer solutions at $\mathrm{pH}=7$ and $\mathrm{pH}=4$. The probes were connected to a solid-state data logger (Gastric $\mathrm{pH}$ monitoring system, $\mathrm{pH}$ day2 $\mathrm{PH}-\mathrm{HS}$, Menfis BioMedica s.r.l, Venezia, Italy) with an event marker to document meals, symptoms, and body recumbency. The $\mathrm{pH}$ probe was inserted transnasally and advanced until an acidic gastric $\mathrm{pH}<2.5$ was reached. The $\mathrm{pH}$ probe was subsequently withdrawn slowly until the $\mathrm{pH}$ sensor was positioned $5 \mathrm{~cm}$ above the previously determined upper border of the lower esophageal sphincter. Subjects were encouraged to undergo normal activities, sleep schedules, and meal times. A normal diet was encouraged, but subjects were asked to refrain from acidic food or drinks, as well as alcohol. They were also asked to remain as upright as possible when awake, and to lie down flat when asleep. After an interval of 24 hours, subjects were asked to return and the $\mathrm{pH}$ assembly was removed. Data were downloaded into a personal computer. Each individual trace was inspected by one of the authors to ensure good quality and the absence of artifacts. Data were analysed by proprietary software (Multigram version 6.31, Gastrosoft Inc., Stockholm, Sweden). Acid reflux was defined as an esophageal $\mathrm{pH}<4$ for at least 7.5 seconds. The reflux episode was considered to have terminated if $\mathrm{pH} \geq 4$. The six $\mathrm{pH}$ parameters proposed by Johnson and Demeester 4 were evaluated for the channel positioned $5 \mathrm{~cm}$ above the upper border of the lower esophageal sphincter.

Table 1. Demographic Data of the 30 Healthy Subjects in whom Ambulatory pH Measured

\begin{tabular}{|c|c|c|c|c|c|c|c|c|}
\hline & \multicolumn{5}{|c|}{ Age group } & \multirow{2}{*}{$\begin{array}{l}\text { Body length, cm } \\
\text { (median) }\end{array}$} & \multirow{2}{*}{$\begin{array}{l}\text { Body weight, kg } \\
\text { (median) }\end{array}$} & \multirow{2}{*}{ BMI (median) } \\
\hline & $21-30(\mathrm{n})$ & $31-40(n)$ & $41-50(\mathrm{n})$ & $51-60(\mathrm{n})$ & $\Sigma(\mathrm{n})$ & & & \\
\hline Men & 6 & 1 & 2 & 2 & 11 & 175 & 68 & 21.3 \\
\hline Women & 4 & 2 & 6 & 7 & 19 & 158 & 61 & 24.9 \\
\hline$\Sigma$ or median & 10 & 3 & 8 & 9 & 30 & 164 & 63 & 23.6 \\
\hline
\end{tabular}

$\sum$, sum. 


\section{Statistical analysis}

Normal values for each of the parameters were assessed by calculating the 95th percentile for the subject group. Relation between age, sex, weight, height, and BMI and various reflux parameters was tested by multiple regression analysis after Spearman correlation. The MannWhitney test and Kruskal-Wallis test were used in a comparison according to sex and age with regard to various reflux parameters. Statistical analyses were performed using the Statistical Package for Social Science (Windows version 12.0, SPSS Inc., Chicago, US). A p value $<0.05$ in a double-sided test was considered to be significant.

\section{RESULTS}

Forty-two healthy subjects were recruited and thirty subjects (11 male; median age, 47.0 years; age range, 2260 years) were finally analyzed after the drop-out with reflux esophagitis on upper endoscopy (one person), high points $>8$ of reflux finding score (two persons) and technical errors (one person) or self-stop of measurement (eight persons) of ambulatory esophageal $\mathrm{pH}$ study. The demographic data of these subjects is shown in Table 1 . There was no sex difference seen in the age, body length, body weight, and BMI in the mean values. The 95th percentile for reflux parameters assessed in the distal esophagus were: percent total time $\mathrm{pH}<4,5.10 \%$; percent up-

Table 2. 24-hour pH Values of Healthy Volunteers

\begin{tabular}{lcc}
\hline \multicolumn{1}{c}{ Variable } & All subjects* & 95th percentile \\
\hline \% total & $0.35(0-5.7)$ & 5.10 \\
\% upright & $0.80(0-8.1)$ & 7.88 \\
$\%$ supine & $0.18(0-4.6)$ & 4.00 \\
Total episodes (n) & $11.0(0-94)$ & 62.7 \\
Episodes >5 min (n) & $0.0(0-8.0)$ & 5.3 \\
Longest episodes (min) & $1.9(0-27.1)$ & 21.3 \\
\hline
\end{tabular}

*Data are shown as median (range). right time $\mathrm{pH}<4,7.88 \%$; percent supine time $\mathrm{pH}<4$, $4.00 \%$; number of reflux episodes, 62.7 ; number of reflux episodes with $\mathrm{pH}<4$ for $>5$ minutes, 5.3 ; and the longest single acid exposure episode, 21.3 minutes (Table 2). The Mann-Whitney test was used to evaluate the influence of gender and age on the normal $\mathrm{pH}$ parameters. Table 3 reveals that women consistently produced higher median values than men on all $\mathrm{pH}$ parameters with significance except for percentage of supine acid exposure time and the number of episodes $>5$ min with near significance. The median $\mathrm{pH}$ values tended to be higher among the older (41-60 years old) subjects except for the parameters of total number of reflux episodes and percentage of supine acid exposure time. However, no significant effects of age were found. Fig. 1 shows the relationship between age, gender, and percent total esophageal acid exposure that women tended to have more esophageal acid reflux than men particularly in the older (41-60 years old) than younger (21-40 years old). These relationships between gender and age and the esophageal $\mathrm{pH}$ parameters may be better understood by examining

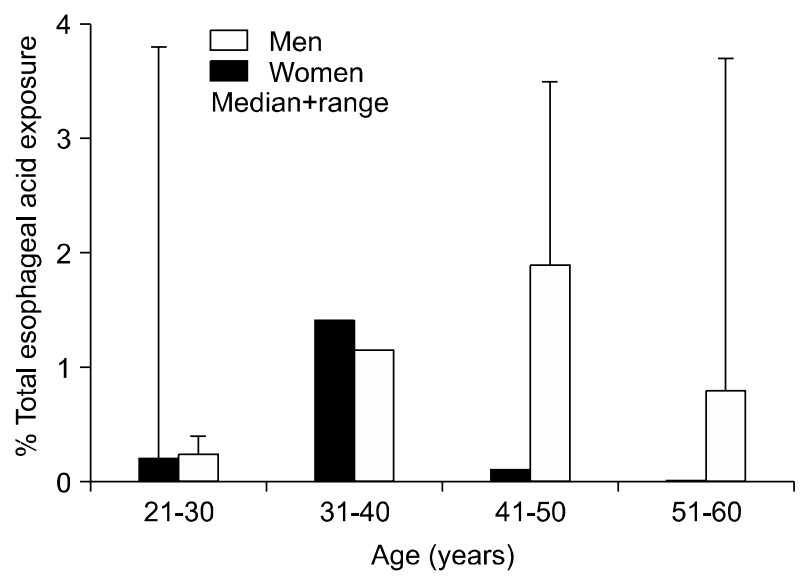

Fig. 1. Relationship between age, gender, and percentage total esophageal acid exposure measured by 24-hour ambulatory $\mathrm{pH}$ monitoring in 30 healthy volunteers. Esophageal acid reflux is more common in older women than in older men.

Table 3. 24-hour pH Values of Healthy Volunteer in Relation to Sex and Age

\begin{tabular}{|c|c|c|c|c|c|c|}
\hline \multirow{2}{*}{ Variable } & \multicolumn{2}{|c|}{ Sex } & \multirow{2}{*}{$\mathrm{p}$ value } & \multicolumn{2}{|c|}{ Age } & \multirow{2}{*}{$\mathrm{p}$ value } \\
\hline & Male* & Female* & & $21-40$ years* & $41-60$ years* & \\
\hline$\%$ total & $0.10(0-3.8)$ & $0.70(0-5.7)$ & 0.04 & $0.30(0-3.8)$ & $0.40(0-5.7)$ & 0.51 \\
\hline$\%$ upright & $0.19(0-3.9)$ & $0.90(0-8.1)$ & 0.03 & $0.29(0-3.9)$ & $0.90(0-8.1)$ & 0.36 \\
\hline$\%$ supine & $0.05(0-3.5)$ & $0.37(0-4.6)$ & 0.07 & $0.18(0-3.5)$ & $0.17(0-4.6)$ & 0.87 \\
\hline Total episodes (n) & $2.3(0-94)$ & $13.0(1-37)$ & 0.04 & $12.0(0-94)$ & $6.0(0-37)$ & 0.81 \\
\hline Episodes $>5 \min (\mathrm{n})$ & $0.2(0-2.0)$ & $0.4(0-8.0)$ & 0.53 & $0.0(0-2.0)$ & $0.0(0-8.0)$ & 0.34 \\
\hline Longest episodes (min) & $0.8(0-12.4)$ & $2.3(0.1-27.1)$ & 0.03 & $1.1(0-12.4)$ & $2.4(0-27.1)$ & 0.12 \\
\hline
\end{tabular}

*Data are shown as median (range). 
Table 4. 24-hour $\mathrm{pH}$ Values with Interaction between Sex and Age

\begin{tabular}{lccccc}
\hline & YM (n=7) & YW (n=6) & OM (n=4) & OW (n=13) & $\mathrm{p} \mathrm{value}^{\dagger}$ \\
\hline \% total & $0.30(0-3.8)$ & $0.40(0-1.5)$ & $0.05(0-0.1)$ & $1.50(0.1-5.7)$ & 0.03 \\
$\%$ upright & $0.29(0-3.9)$ & $0.58(0-1.6)$ & $0.05(0-0.2)$ & $1.52(0-8.1)$ & 0.02 \\
$\%$ supine & $1.08(0-3.5)$ & $0.28(0-0.8)$ & $0.02(0-0.1)$ & $0.49(0-4.6)$ & 0.13 \\
Total episodes (n) & $12.0(0-94)$ & $12.0(1-33)$ & $0.7(0-3)$ & $13.0(2-37)$ & 0.05 \\
Episodes >5 min (n) & $0.33(0-2.0)$ & $0.00(0-0)$ & $0.00(0-0)$ & $0.60(0.8)$ & 0.12 \\
Longest episodes (min) & $1.1(0-12.4)$ & $1.3(0.1-2.4)$ & $0.47(0-1.2)$ & $3.3(1.0-27.1)$ & 0.01 \\
\hline
\end{tabular}

*YM, young men; YW, young women OM, old men; OW, old women.

${ }^{\dagger}$ Kruskal-Wallis test (chi-square approximation).

Data are shown as median (range).

Table 4. This table shows a significant interaction of age and gender on the longest episodes $(p=0.01)$, in which the older women produced the highest median values on this parameter. Thus, the older women were primarily responsible for the significant effect of gender on the longest episodes. A similar interaction that approached significance $(p=0.03)$ also was found on percentage of total acid exposure. The older women were primarily responsible for the strong tendency of women to display higher percentage of total acid exposure than men $(p=0.04)$. With regard to total number of episodes and number of episode $>5$ minutes, however, the age and gender interactions did not even approach significance $(p=0.05$ and $\mathrm{p}=0.12$, respectively) although the strong tendency of highest number in older women. Body length, body weight, and BMI were not associated with differences in the reflux parameters.

\section{DISCUSSION}

The results of our healthy volunteer study quantifying the amount of physiologic GER in 30 healthy subjects can be summarized as follows: The 95th percentile for percent total time $\mathrm{pH}<4$ assessed in the distal esophagus was $5.10 \%$ and body length, body weight and BMI are not associated with $\mathrm{pH}$ parameters. These results have an important implication for both clinical and research purposes in Korean.

A major concern in the process of establishing levels of normality is a sample size. However, laryngoscopy, upper gastrointestinal endoscopy and ambulatory 24-hour esophageal $\mathrm{pH}$ monitoring are somewhat invasive tests for volunteers, therefore, it is very difficult to select a representative sample of a sufficient size.

Recently, Smout et al. ${ }^{8}$ compared 16 young healthy volunteers (mean age 31 years) and a similar number of healthy older volunteers (mean age 61 years, range 45-73 years) without the problem of restricted age ranges in the two previous studies. ${ }^{9,10}$ The subjects were composed of
16 males and 16 females. The older subjects showed significantly higher values in the total and upright percentage of time of $\mathrm{pH}<4$ and the total number of reflux episodes $>5 \mathrm{~min}$. However, gender effect was not evaluated in these $\mathrm{pH}$ parameters.

Richter et al. $^{5}$ got over limitations of these previous studies. All of subjects were healthy, the older was large in size $(n=24)$, and the group were considerably different in age (youngers' mean age 36 years, range 29-49 years; olders' mean age 64 years, range 50-84 years). Compared with the results by Smout et $a l^{8}{ }^{8}$, an independent effect of age was not noted in $\mathrm{pH}$ parameters. However, the older males produced the highest values in the total number of episodes $>5 \mathrm{~min}$ and longest reflux episode.

Our study has the more distinctively healthy subjects than the study by Richter et al..$^{5}$ All of our subjects were free from upper gastrointestinal and airway complaints as proven by validated questionnaire, significant sign of laryngeal disease on the laryngoscopic examination by two otorhinolaryngologest, and esophagogastric organic disease on the upper endoscopic examination. Among the exclusion criteria in our study, smoking was noted that previous studies had not excluded smoker from the enrollment. The groups according to age were substantially different in age (younger controls' mean age 28 year, range 22-38 year, $\mathrm{n}=13$; older controls' mean age 52 years, range $45-60$ years, $n=17$ ), however, the much older subjects over 60 years old were not included in analysis.

In our study, although age does not significantly influence $\mathrm{pH}$ parameters, the median $\mathrm{pH}$ values tended to be higher among the older subjects except for the parameters of total number of reflux episodes and percentage of supine acid exposure time. As opposed to Richter et al., age and gender showed strong interaction on the longest episodes and percentage of total acid exposure in which the older women produced the greater values on these parameters. We also found that women showed the significantly higher percentage of acid exposure time, total number of episodes, and longest time of episodes than 
Table 5. Reflux Parameters Measured $5 \mathrm{~cm}$ above the Lower Esophageal Sphincter, and Comparisons with the Results of Other Studies

\begin{tabular}{lccccc}
\hline \multicolumn{1}{c}{ Reflux parameter* } & Our study & Kim et al. ${ }^{12}$ & Hu et al. ${ }^{13}$ & Richter et al. $^{5}$ & Johnson and Demeester $^{4}$ \\
\hline \% total & 5.10 & 3.63 & 4.6 & 5.78 & 4.2 \\
\% upright & 7.88 & 5.93 & 7.0 & 8.15 & 6.3 \\
\% supine & 4.00 & 7.55 & 4.5 & 1.20 & 1.2 \\
Total episodes (n) & 62.7 & 92.8 & 73.0 & 46.00 & 50.0 \\
Episodes >5 min (n) & 5.3 & 1.0 & 4.0 & 4.0 & 3.0 \\
Longest episodes (min) & 21.3 & 30.5 & 11.2 & 18.45 & 9.2 \\
\hline
\end{tabular}

*95th \%.

men.

However, a power analysis suggests that approximately 100 older and 100 younger subjects would need to be studied to detect an age effect with $80 \%$ power at a $\mathrm{p}$ value $<0.05$. $^{11}$ In addition, the distribution of ages were considerably different between men and women in our study and it should be noted that the different effect of gender on reflux parameters probably was due to more dominant distribution to older group in number of women than men. Thus, for clinical purposes, we do not believe that age and gender generally has an important effect on the physiologic parameters of acid reflux through our study alone. Further investigation including race difference is needed for these probable effects of age and gender on reflux parameters.

Table 5 shows the various normal values of reflux parameters as 95th percentile at four studies compared with our study. ${ }^{4,5,12,13}$ Many factors including a variety of characteristics of subjects, differences of tools and techniques of measurement and real population difference in gastroesophageal reflux should contribute to these results.

Limitation of our study is that it represents "supernormal" values rather than values from a cross section of the general population. Characterization of reflux patterns in the general population have been limited. The largest study is by the survey by Cho et al. ${ }^{14}$ of 2024 Korean individuals. These study found that $4.71 \%$ of the representative sample's complained of heartburn at least once a month and $2.0 \%$ at least once a week as criteria of gastroesophageal reflux disease. Therefore, our definition for abnormal frequency of heartburn (no episodes in the last month) might be extremely normal criterion.

In conclusion, we believe that these normal esophageal $\mathrm{pH}$ values will have a broad application in clinical and research studies in Korea and abroad. Our data based on thirty healthy subjects studied with commercially available equipment and standardized methodology should allow greater confidence in identifying patients with gastroesophageal reflux disease. Nevertheless, no database can be perfect because of the well-known variability of acid exposure from day to day and the inherent problems with the $\mathrm{pH}$ probe.

\section{REFERENCES}

1. Rokkas T, Sladen GE. Ambulatory esophageal pH recording in gastroesophageal reflux: relevance to the development of esophagitis. Am J Gastroenterol 1988;83:629-632.

2. Lam HG, Breumelhof $R$, van Berge Henegouwen GP, Smout AJ. Temporal relationships between episodes of non-cardiac chest pain and abnormal oesophageal function. Gut 1994;35:733-736.

3. Lam HG, Breumelhof R, Roelofs JM, Van Berge Henegouwen GP, Smout AJ. What is the optimal time window in symptom analysis of 24-hour esophageal pressure and $\mathrm{pH}$ data? Dig Dis Sci 1994;39:402-409.

4. Johnson LF, Demeester TR. Twenty-four-hour pH monitoring of the distal esophagus. A quantitative measure of gastroesophageal reflux. Am J Gastroenterol 1974;62:325-332.

5. Richter JE, Bradley LA, DeMeester TR, Wu WC. Normal 24-hr ambulatory esophageal $\mathrm{pH}$ values. influence of study center, pH electrode, age, and gender. Dig Dis Sci 1992;37: 849-856.

6. Blafsky PC, Postma GN, Koufman JA. Validity and reliability of the reflux symptom index (RSI). J Voice 2002;16: 274-277.

7. Blafsky PC, Postma GN, Koufman JA. The validity and reliability of the reflux finding score (RFS). Laryngoscope 2001;111:1313-1317.

8. Smout AJPM, Breedijk M, Van der Zouw C, Akkermans LMA. Physiological gastroesophageal reflux and esophageal motor activity studied with a new system for 24-hour recording and automated analysis. Dig Dis Sci 1989;34: 372-378.

9. Spence RAJ, Collins BJ, Parks TG, Love AHG. Does age influence normal gastro-oesophageal reflux. Gut 1985;26: 799-801.

10. Kruse-Andersen S, Wallin L, Madsen T. The influence of age on esophageal acid defense mechanisms and spontaneous acid gastroesophageal reflux. Am J Gastroenterol 1988;83:637-639.

11. Cohen J, Cohen P. Applied multiple regression/correlation analysis for the behavioral sciences. Hillsdale, New Jersey: Lawrence Erlbaum, 1975.

12. Kim YH, Song CW, Kim YS, et al. 24 hour ambulatory 
esophageal dual probe $\mathrm{pH}$ monitoring in healthy adults. Korean J Gastroenterol 2001;37:1-6.

13. Hu WHC, Wong NYH, Hui WM, et al. Normal 24-hour ambulatory proximal and distal gastroesophageal reflux parameters in Chinese. Hong Kong Med J 2002;8:168-171.
14. Cho YS, Choi MG, Jeong JJ, et al. Prevalence and clinical spectrum of gastroesophageal reflux: a population-based study in Asan-si, Korea. Am J Gastroenterol 2005;100: 747-753. 